\title{
Article \\ Transforming a Didactic Lecture into a Student-Centered Active Learning Exercise-Teaching Equine Diarrhea to Fourth-Year Veterinary Students
}

\author{
Stuart J. G. Gordon ${ }^{1, * \mathbb{D}}$, Charlotte F. Bolwell ${ }^{1}{ }^{\mathbb{C}}$, Jessica L. Raney ${ }^{1}$ and Nick Zepke ${ }^{2}$ \\ 1 School of Veterinary Science, Massey University, Palmerston North 4442, New Zealand; \\ C.Bolwell@massey.ac.nz (C.F.B.); jraney04@gmail.com (J.L.R.) \\ 2 Institute of Education, Massey University, Palmerston North 4442, New Zealand; N.Zepke@massey.ac.nz \\ * Correspondence: s.j.g.gordon@massey.ac.nz
}

Citation: Gordon, S.J.G.; Bolwell, C.F.; Raney, J.L.; Zepke, N.

Transforming a Didactic Lecture into a Student-Centered Active Learning Exercise-Teaching Equine Diarrhea to Fourth-Year Veterinary Students. Educ. Sci. 2022, 12, 68. https:// doi.org/10.3390/educsci12020068

Academic Editor: James Albright

Received: 24 November 2021

Accepted: 17 January 2022

Published: 20 January 2022

Publisher's Note: MDPI stays neutral with regard to jurisdictional claims in published maps and institutional affiliations.

Copyright: (C) 2022 by the authors. Licensee MDPI, Basel, Switzerland. This article is an open access article distributed under the terms and conditions of the Creative Commons Attribution (CC BY) license (https:// creativecommons.org/licenses/by/ $4.0 /)$.

\begin{abstract}
Problem-solving abilities, creative and critical thinking, communication skills, and teamwork are now recognized as fundamental determinants of professional success, especially in vocational professions, such as veterinary science. Tertiary education is now obliged to provide opportunities for students to become proficient in these qualities. With this in mind, the principal author, an equine science senior lecturer, attempted to increase student engagement by developing a new active learning, student-centered one-hour teaching episode on 'equine diarrhea', to replace the traditional didactic lecture format. The aim of the study, therefore, was to share the principal author's journey in the development and implementation of this active learning episode and to explain why it represents a simple but effective method of promoting student engagement. In addition, the adaptation of this method into an online teaching and learning format is briefly discussed. The effectiveness of this active learning method is also explored by comparing it with the traditional didactic method of delivery. Students in the active learning class reported that the learning activity had enhanced their skills in clinical reasoning, problem-solving, and communication. They also described themselves as active participants in the learning process. Students in the traditional didactic class reported that they were satisfied with the time allocated to the lecture, felt that the lecture was well organized and managed, and subsequently felt adequately prepared to answer conventional examination questions relating to equine diarrhea. Other issues, such as student resistance to changes in teaching formats, the effectiveness of group work or teamwork, levels of student confidence within an active learning environment, and the importance of high-quality facilitation during active learning activities, are also discussed in this paper. Although the active learning method described is not novel, the authors hope that fellow educators, across any tertiary discipline, might find that the method described represents a quick and simple method of transforming a single didactic lecture into an enjoyable and engaging learning activity.
\end{abstract}

Keywords: equine diarrhea; problem-solving; active learning; student-centered; didactic teaching; clinical reasoning; veterinary undergraduate teaching; voice over internet protocols; video conferencing

\section{Introduction}

Traditionally, veterinary schools have assumed the role of content experts in the veterinary curriculum and have imparted this information to students who adopt a passive role in the process [1]. There is, however, increasing recognition for veterinary education to focus on the ability to find and apply information instead of the straightforward transmission of the ever-expanding curriculum content [2]. Research on student learning has shown that there is a positive correlation between deep, meaningful, and elaborated learning and students' ability to retain and apply knowledge to new problems [2]. Problem-solving abilities, creative and critical thinking, communication skills, and teamwork are now recognized as fundamental determinants of professional success and tertiary education must now provide 
opportunities for students to become proficient in these qualities [3]. Vocational degree programs such as veterinary degrees, therefore, have two obligations: to teach students what to know, and also, how to know [4]. Students should become active discoverers and constructors of their own knowledge with the teacher creating environments and experiences that help to achieve this [5]. Newble and Entwistle [6] suggested that veterinary schools had an obligation to provide opportunities for students to integrate their learning into conceptual frameworks characterized by relevant and realistic scenarios, arguing that this was the type of learning most useful to veterinary practitioners engaging in continuing professional development.

The current coronavirus pandemic has necessitated a transition to distance learning and online pedagogies [7]. Many lectures are now delivered using a live video-conferencing format, or Voice over Internet Protocols (VoIPs), such as Zoom (Zoom Video Communications, Inc.) or Teams (Microsoft Corporation). The move to online learning should favor a change in focus from content delivery to case-based and problem-based learning, and the promotion of critical thinking and reflective practice. Anecdotally, many lecturers seem to have instead resorted to using the live video-conferencing format in a didactic fashion. This usually involves talking uninterrupted, over screen-shared PowerPoint slides, to a sea of online students who have often switched off their cameras and muted their microphones.

Even prior to the coronavirus pandemic, the Equine Veterinary Clinical Studies course at the Massey University School of Veterinary Science had adopted a more integrated mode of teaching and learning using a blend of online and traditional face-to-face components. The intention was to facilitate the delivery of a learning experience for students that most resembles the way information and problems are encountered in the workplace. It is imperative that veterinary students emerge from their training programs equipped with the knowledge and skills that are relevant to a constantly changing workplace [8].

In line with the Equine Veterinary Clinical Studies' integrated approach to teaching, the principal author attempted to increase student engagement by developing a new learner-centered teaching episode on 'equine diarrhea', to replace the traditional didactic lecture format. This single one-hour learning episode utilized a clinical case scenario and involved group-work and problem-solving. The framework was based on the 'flipped learning' model as outlined by Birgili and associates [3]. Flipped learning helps to establish a novel framework within which students can receive personalized education appropriate for their learning needs. The flipped learning environment is dependent on the input of the facilitator/instructor and the interaction and collaboration by students [3]. Although this learning episode was created for in-person delivery, just prior to the coronavirus epidemic, it is felt that the novel teaching approach remains relevant to the predominantly online learning environment prevailing today.

The aim of this paper, therefore, is to share the principal author's journey in the development and implementation of this learning episode (teaching 'equine diarrhea' to fourth-year veterinary students) and to explain why it represents a simple but effective method of promoting student engagement. The effectiveness of this active learning teaching method is also explored by comparing it with the traditional didactic method of teaching. In addition, the adaptation of this method into an online teaching and learning format is briefly discussed. The authors make no claim to have developed a pioneering new teaching method but hope that teaching colleagues, across any tertiary discipline, may agree that this technique represents a quick and simple method of transforming a single didactic lecture into an enjoyable and engaging learning activity.

\section{Developing the Learner-Centered Teaching Episode}

The following steps were taken in the development of the active learning teaching episode: 


\subsection{Adopting an Appropriate Learning Theory}

The learner-centered approach adopted for this teaching and learning episode borrowed heavily from the adult learning theory of andragogy [9]. Andragogy is grounded in humanistic learning theories with learning focused on the individual and on selfdevelopment [10]. Learners assume primary responsibility for their own learning with the process of learning centered on learners' needs rather than on subject content [10]. In addition, the learners' pre-existing knowledge is exploited as this serves as an important internal influence on learning. The teaching exercises employed in this learning episode, therefore, required learners to initially draw on their previous experience in the construction of new knowledge, attitudes, and skills to enable them to answer questions and solve problems in a realistic professional context [11].

\subsection{Developing Appropriate Learning Outcomes}

It was important to develop clear and transparent learning outcomes (LOs) for this learning episode that specified the activities (and the content the activities referred to) that students should engage in to achieve the intended outcome. The learning activities were designed to enhance communication, self-management, and interpersonal skills, thus recognizing their critical importance in veterinary professional life and in the application of knowledge and skills [12]. It was also essential to ensure that the LOs were achievable in the limited time available (one hour) and that they reflected the reality that students did not need to qualify as experts in the lecturer's field [13]. Examples of LOs developed for this learning episode included:

'The learner should be able to investigate a case of equine diarrhea in a logical, and systematic manner, developing an appropriate list of disease conditions (through the summation of pertinent diagnostic findings)'; and: 'The learner should be able to rapidly access and utilize equine veterinary science information relevant to the case using appropriate media and technologies'.

\subsection{Assigning Roles for Group Members}

The fourth-year veterinary class was divided into six groups, each consisting of approximately eight students. At the start of the lesson, each group selected a 'leader', whose task was to coordinate the group activities and a 'speaker' who was required to verbally represent the group during class discussions. A 'timekeeper' was also appointed who had to ensure the group fulfilled each task within the time allocated. Finally, a 'cheerleader' was chosen whose mandate was to motivate the group and encourage group members to collaborate effectively. This assignment of roles within each group accommodated the wide range of abilities and personality types present across the student body.

\subsection{Initiating the Learning Episode}

In line with the principles of andragogy, an icebreaker exercise was conducted at the beginning of the learning episode that required students to reflect on their current knowledge of equine diarrhea and to consider how they could approach cases of diarrhea in horses within the stipulated context. This afforded the students the opportunity to make connections with any new material and with their existing cognitive structures [14]. The icebreaker exercise also involved a brief period of informal chat between the facilitator and the class and amongst group members. This provided an opportunity for students to engage with the facilitator, and with one another, to discover each other's experiences, beliefs, and attitudes [15].

\subsection{Presenting a Series of Tasks/Challenges to the Students}

A series of tasks on equine diarrhea were developed for the learning episode that exposed the students to methods of clinical reasoning while providing them with a framework for the organization of knowledge [16]. The tasks/challenges were presented to the students, working within their groups, in a sequential fashion, over the course of the lesson. 
The order of presentation of the tasks allowed the clinical case of diarrhea in a horse to be slowly built up and provided the opportunity for the students to approach the case in a logical and sequential manner. It was hoped that the emphasis on contextual learning and clinical relevancy would help to enhance the students' motivation to learn and to generate the kind of elaborated knowledge necessary in veterinary medicine [17].

Examples of questions presented to the groups included:

'Explain the pathogenesis of diarrhea using an infectious and a non-infectious aetiological agent as an example'; and: 'Formulate three important questions that you must ask the horse owner when taking a history during the investigation of a case of equine diarrhea (consider risk factors for a horse developing diarrhea when attempting this task)'.

It was critical that the time limits allocated to each task were adhered to so that all the tasks could be addressed in the one hour allocated to this exercise. A total of ten short tasks were presented to the students during the learning episode allowing about 5 min for each task. Each task required the students to quickly research the topic and formulate a response within the limited time available. A minute at the end of each session was dedicated to feedback by the students. The speaker of one of the groups had to quickly present their findings to all the other groups. It was arranged so that the speakers of each group had at least one chance of presenting their group's response to the whole class during the learning episode. A worksheet (hard copies and digital versions), containing the tasks (with space available to make notes and to record answers) was supplied to each student.

The clinical problems encouraged students to develop clinical reasoning skills by acquiring facts, identifying problems, generating hypotheses, and identifying additional learning needs that pertained to the pathophysiology, diagnostics, treatment, and prognosis of the clinical case [16]. The learners had full access to the Massey University online learning environment that contained links to relevant readings and websites.

While the students were working on their cases, the principal author moved between groups acting as a roaming facilitator. The aim was to promote an environment of inquiry by asking probing, reflecting, and involving questions that stimulated interest and motivated the students to continue [18]. The staff facilitator also helped students to address any issues with interpersonal group dynamics, such as disruptive student behavior [18].

\section{Determining the Effectiveness of This Teaching Episode}

To ascertain the effectiveness of this teaching method, a comparison was made between the new learner-centered approach and the traditional didactic teaching approach.

\subsection{Study Design}

The class of 103 fourth-year veterinary students at Massey University was split randomly into two groups of 51 students and 52 students, respectively. The group containing 51 students received a traditional didactic teacher-centered lecture (presented by the principal author), on equine diarrhea, during a one-hour lecture period. The group containing 52 students were taught the same topic, by the same teacher, during another one-hour lecture period using the new student-centered active learning approach outlined above. Since this exercise occurred prior to the coronavirus pandemic, both learning episodes were conducted in-person within traditional lecture theaters.

The data collection involved the use of a purpose-designed four-point Likert scale questionnaire containing 17 statements (Table 1). At the end of each teaching and learning episode, students from both groups were asked to complete the questionnaire to solicit their opinion on the suitability of each teaching format for learning about equine diarrhea. Participants were asked to signal their level of agreement for each given statement (Table 1). Their opinions were sought on whether the teaching format facilitated the process of clinical reasoning and enhanced problem-solving skills. The questionnaire was also designed to determine student opinion on whether the LOs were constructively aligned with the teaching and learning activities. Finally, the questionnaire was used to solicit student opinion on the effectiveness of the facilitation and whether instructions given in the learning 
episode were clear and easy to understand. One open-ended question seeking further comments about the suitability of each teaching style was included at the end.

Table 1. Student responses to the 17 statements in the questionnaire.

\begin{tabular}{|c|c|c|c|c|c|c|c|c|}
\hline \multirow{3}{*}{ Statements } & \multicolumn{8}{|c|}{ Number of Student Responses } \\
\hline & \multicolumn{2}{|c|}{$\begin{array}{l}1 \text { (Strongly } \\
\text { Agree) }\end{array}$} & \multicolumn{2}{|c|}{2 (Agree) } & \multicolumn{2}{|c|}{3 (Disagree) } & \multicolumn{2}{|c|}{$\begin{array}{l}4 \text { (Strongly } \\
\text { Disagree) }\end{array}$} \\
\hline & AL & DL & AL & DL & AL & DL & $\mathbf{A L}$ & DL \\
\hline The objectives of this learning episode were clear & 22 & 35 & 17 & 9 & 0 & 0 & 0 & 0 \\
\hline $\begin{array}{l}\text { The learning episode was appropriate for a fourth-year } \\
\text { veterinary undergraduate equine studies class }\end{array}$ & 25 & 36 & 14 & 8 & 0 & 0 & 0 & 0 \\
\hline $\begin{array}{l}\text { The format of this learning episode was suitable for the } \\
\text { teaching of equine diarrhea }\end{array}$ & 22 & 23 & 17 & 21 & 0 & 0 & 0 & 0 \\
\hline $\begin{array}{l}\text { The learning episode used realistic clinical scenarios that } \\
\text { could be expected to be faced by a veterinary graduate }\end{array}$ & 23 & 18 & 15 & 26 & 0 & 0 & 0 & 0 \\
\hline $\begin{array}{c}\text { The learning episode was a valuable experience in terms } \\
\text { of preparing me to face a real clinical situation as a } \\
\text { qualified veterinarian }\end{array}$ & 18 & 19 & 19 & 22 & 1 & 3 & 0 & 0 \\
\hline $\begin{array}{c}\text { The learning episode format was appropriate to } \\
\text { adequately prepare me for conventional exam } \\
\text { questions * }\end{array}$ & 6 & 25 & 28 & 18 & 5 & 1 & 0 & 0 \\
\hline $\begin{array}{l}\text { The format of this learning episode facilitated the } \\
\text { recalling of factual information }\end{array}$ & 21 & 13 & 17 & 26 & 1 & 5 & 0 & 0 \\
\hline $\begin{array}{l}\text { The format of this learning episode facilitated the } \\
\text { process of clinical reasoning * }\end{array}$ & 27 & 12 & 12 & 22 & 0 & 9 & 0 & 0 \\
\hline $\begin{array}{l}\text { This learning episode enhanced my problem-solving } \\
\text { skills * }\end{array}$ & 13 & 4 & 23 & 17 & 3 & 23 & 0 & 0 \\
\hline $\begin{array}{l}\text { This learning episode enhanced my communication } \\
\text { skills * }\end{array}$ & 7 & 0 & 26 & 10 & 6 & 25 & 0 & 9 \\
\hline $\begin{array}{l}\text { This learning episode helped to integrate knowledge } \\
\text { from previous learning episodes }\end{array}$ & 20 & 12 & 19 & 24 & 0 & 6 & 0 & 2 \\
\hline $\begin{array}{c}\text { This learning episode actively involved students in the } \\
\text { learning process * }\end{array}$ & 26 & 3 & 12 & 10 & 1 & 24 & 0 & 4 \\
\hline $\begin{array}{c}\text { The instructions given in the learning episode were } \\
\text { clear and easy to understand }\end{array}$ & 28 & 25 & 11 & 19 & 0 & 0 & 0 & 0 \\
\hline $\begin{array}{l}\text { The learning episode was well organised and well } \\
\text { managed by the lecturer * }\end{array}$ & 16 & 35 & 19 & 9 & 4 & 0 & 0 & 0 \\
\hline $\begin{array}{l}\text { The resources (audio-visual and handouts) used in this } \\
\text { learning episode enhanced the lecture making it easier } \\
\text { to understand and helped to reinforce important clinical } \\
\text { concepts }\end{array}$ & 13 & 14 & 23 & 27 & 3 & 3 & 0 & 0 \\
\hline $\begin{array}{c}\text { The time allocated to this learning episode was } \\
\text { sufficient * }\end{array}$ & 0 & 21 & 10 & 21 & 24 & 2 & 5 & 0 \\
\hline $\begin{array}{c}\text { Overall, this learning episode was a positive learning } \\
\text { experience }\end{array}$ & 20 & 24 & 19 & 19 & 0 & 1 & 0 & 0 \\
\hline
\end{tabular}

$\mathrm{AL}$ : Active learning student responses (total number of responses $=40$ ). DL: Didactic lecture student responses (total number of responses $=44$ ). *: Statements that showed a significant difference between the active learning student responses and the didactic lecture student responses at the level of $p<0.003$.

A pilot testing of this questionnaire was conducted with three veterinary students in their final year of study, who had received the traditional equine diarrhea lecture the year before, and with a consultant from the Massey University Centre for Teaching and Learning. 
The questionnaire was modified based on this feedback. This study was conducted with full Massey University Human Ethics Committee approval (Southern B application number 12/09).

\subsection{Data Analysis}

The questionnaire data were analyzed using descriptive statistics to determine the percentage of students who rated each question from 1 to 4 (strongly agree to strongly disagree) on the four-point Likert scale. Chi-square tests or Fisher's Exact tests (for cell numbers $<5$ ) were used to compare the responses of the students attending the studentcentered learning episode and the students attending the didactic lecture, for each question. The results were considered significant at the level of $p<0.003$, with a Bonferroni correction for multiple comparisons. This correction is an adjustment made to $p$-values when several dependent or independent statistical tests are being performed simultaneously on a single data set. The Bonferroni correction was calculated by dividing the $p$-value by the number of comparisons being made.

\subsection{Findings}

There were 44 responses received from the 51 students that attended the traditional didactic lecture and 40 responses received from the 52 students that attended the learnercentered session (representing an $86 \%$ and $80 \%$ response rate, respectively). The responses for each of the statements in the questionnaire are shown in Table 1.

Seven of the seventeen statements showed a significant difference between the active learning student responses and the didactic lecture student responses at the level of $p<0.003$. A breakdown of the responses to the seven statements, for each teaching format, is shown in the stacked column chart in Figure 1.

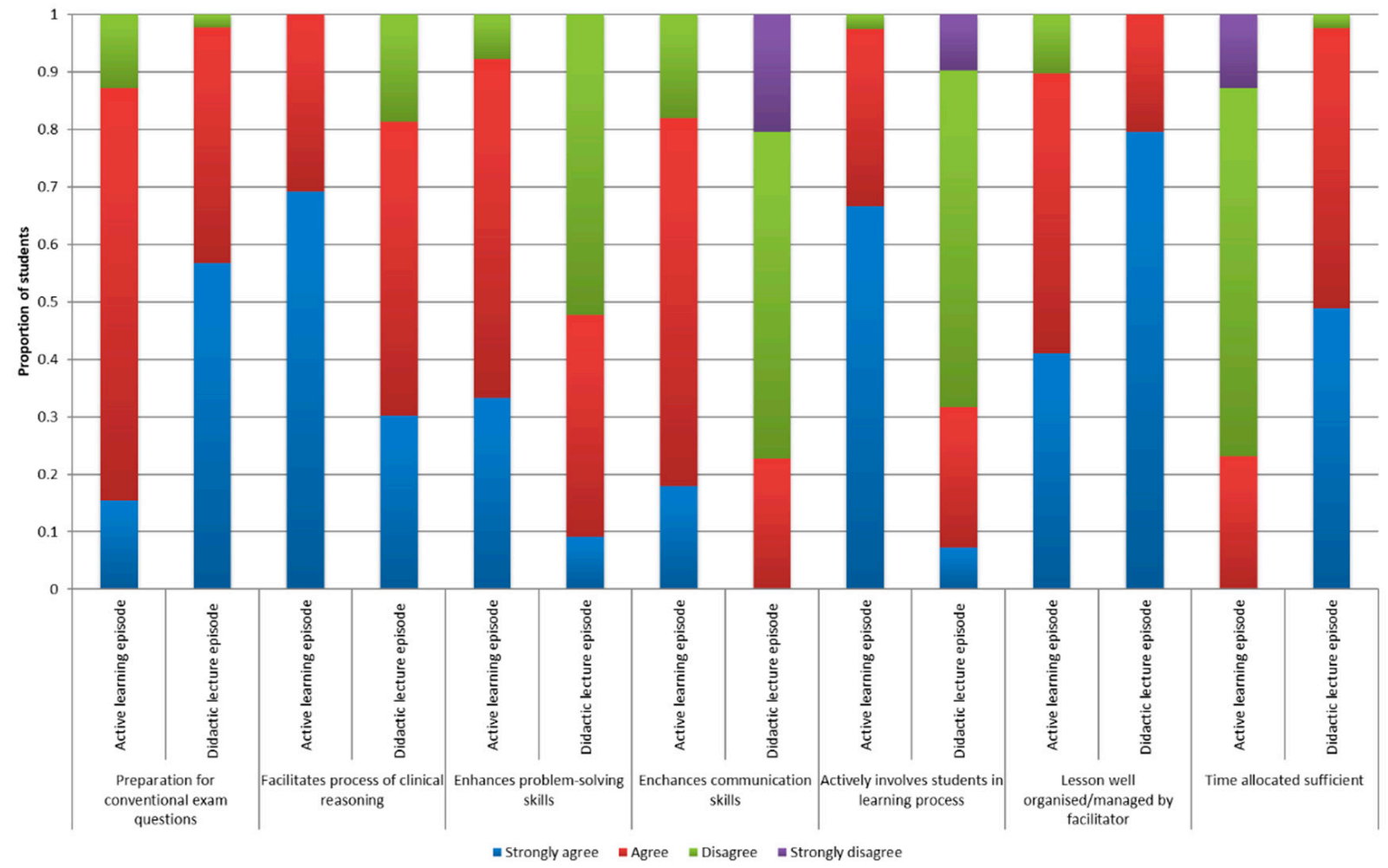

Figure 1. Statements that showed a significant difference between the active learning student responses and the didactic lecture student responses at the level of $p<0.003$.

Figure 2 depicts the seven findings in the form of an organizational chart and highlights the advantages of each teaching style based on the differences in responses for each given 
statement between the active learning students and the didactic lecture students (that were significant at the level of $p<0.003)$.
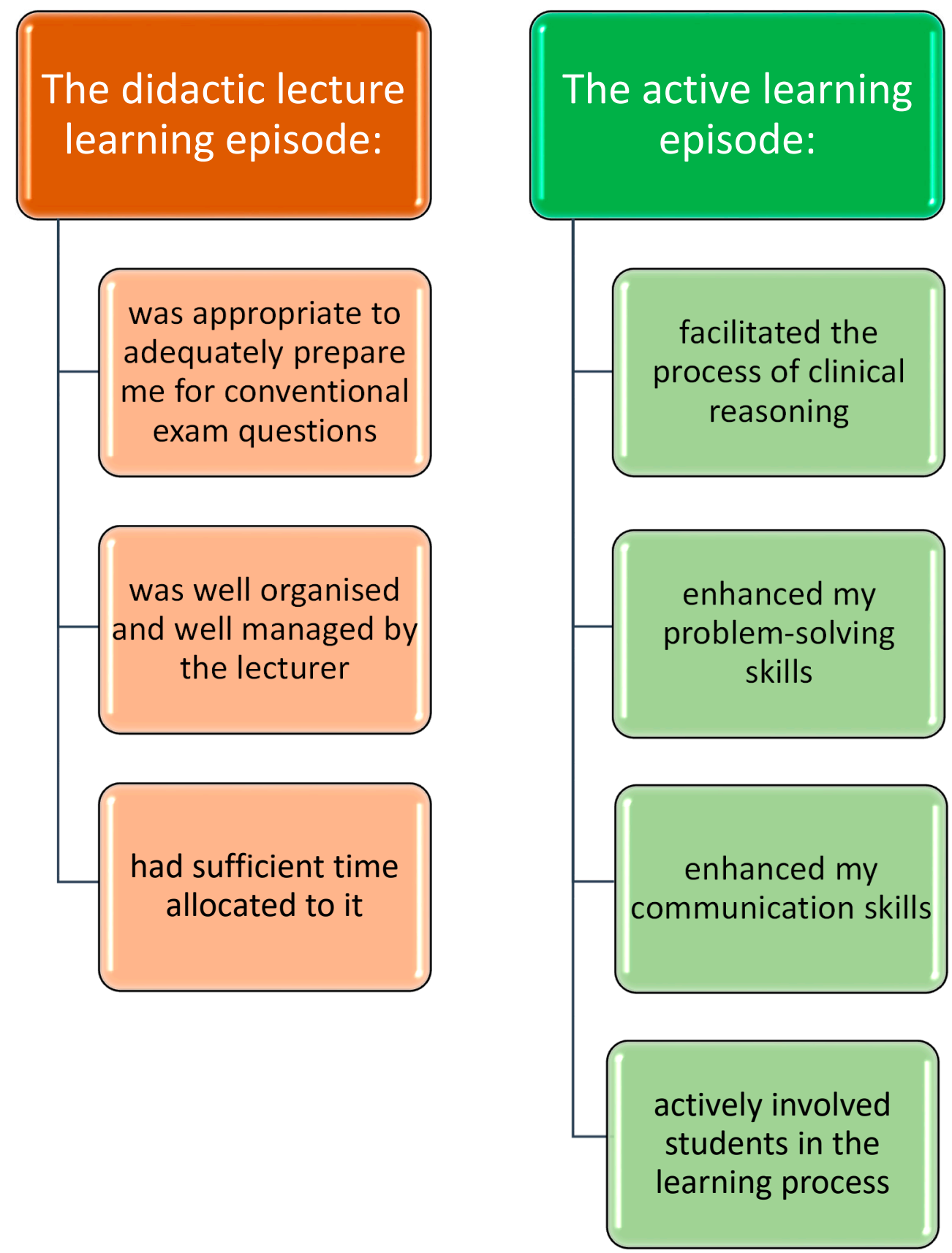

Figure 2. The main advantages of each type of learning episode identified from the students' survey responses.

4. Discussion of Findings and Consideration of Students' Responses to the Open-Ended Question Soliciting Opinion on the Suitability of Each Teaching Style 4.1. Preparedness for Conventional Examination Questions

Figures 1 and 2 illustrate how students who had attended the didactic lecture felt more prepared for conventional examination questions on equine diarrhea after their learning episode compared to students who had attended the active learning teaching episode. This finding was corroborated by Nandi et al. [19] who demonstrated that medical students taught using problem-based learning techniques achieved lower scores in their national medical examinations than medical students instructed using traditional methods. In 
contrast, Bauer et al. [20] discovered that third-year veterinary students in problem-solving groups scored higher in examinations than students in traditional lecture groups, dispelling the notion that lecturing is a more efficient way for students to learn the maximum amount of content-related material.

\subsection{Clinical Reasoning Skills}

The active learning students reported that their learning episode better facilitated their clinical reasoning skills and increased their ability to solve real-world problems compared to those students who attended the didactic lecture (Figure 1, Figure 2). In the open comment section of the survey, students remarked that the active learning episode had: 'Helped me to think like a graduate vet and helped me to prepare for real-life'; and that the teaching method was: ' . . very relevant to a real-life scenario we would experience as vets'. This contrasted with the students receiving the didactic lecture on equine diarrhea, who complained that the learning experience did not provide sufficient clinical application: 'there was no opportunity to apply facts to clinical situations. We could not engage with the subject'.

This elaborated learning, in which knowledge relating to equine medicine is acquired in the context of realistic clinical problems, ensures that information can be retrieved later when dealing with real patients. In contrast, knowledge gained by rote memorisation is difficult to retrieve later in new situations [19].

\subsection{Student Resistance to Changes in Teaching Formats}

Many students expressed concern that the active learning approach could shortchange other aspects of the curriculum, highlighting the fact that many veterinary students still rely on traditional curriculum teaching methods to feel confident in their learning [1]. One active learning student expressed doubt over whether they: ' . . . would ever be able to cover all the course material required in the undergraduate veterinary program if this was the main teaching method'.

Armstrong and Summerlee [21], however, demonstrated that the content knowledge of students working in problem-solving environments is not inferior to that of students taught in traditional lectures designed to transmit knowledge [17]. In addition, soft skills that include coping with uncertainty, appreciating legal and ethical aspects of health care, effective communication, and self-directed learning have been demonstrated to be superior in students taught through problem-solving learning [17]. Moreover, students who answer questions and solve problems in a self-directed and active manner appear to collaborate more effectively in teams outside the classroom, develop greater creativity to solve problems, and gain more resilience by learning from mistakes [18].

While the traditional lecture format may represent a more efficient way for students to learn maximum amounts of content-related material, students who experienced the alternative active learning format reported that: "The amount of content was decreased but content covered was in depth". These students appreciated that: "The instructor seemed to cut out a lot of unnecessary detail which is given in traditional lectures'; and: 'We were not just given a pile of facts to remember'.

Nonetheless, although acknowledging the usefulness of student-centered active learning in integrating course material and facilitating independent discovery, some students felt that this active learning technique should not exclusively replace traditional teaching methods. Tarlinton et al. [22] reported that the problem-solving learning approach has been criticized for allowing gaps to develop in students' basic science knowledge. As a result, many veterinary courses aim for a hybrid experience whereby problem-solving tasks and self-directed learning are incorporated into the curriculum alongside the more structured traditional lectures and practicals [22]. Students in both study cohorts, in the present study, confessed that they would have preferred to have attended both teaching formats. Bauer et al. [20] cautioned, however, that a blended model may result in the self-directed independent study time, essential to student-centered learning success, becoming eroded by the demands of the traditional lecture courses. 
Since many of the active learning students reported feeling anxious about using a new learning method, it is important to be careful and sensitive when introducing any new teaching method. Lane [2] highlighted the fact that the implementation of learning based on completing tasks and solving problems is easier in North American Veterinary schools, as students are enrolled having already completed an undergraduate degree in pre-veterinary subjects. In other countries (such as New Zealand), however, some students enter the veterinary program straight from secondary school and have no prior experience with self-directed learning and problem-solving. Younger veterinary students, straight from school, may find the transition from the traditional school teaching methods to the active learning, student-centered approach process quite challenging [1].

\subsection{Use of External Resources to Access Information}

Students in a passive learning environment tend to make little use of external resources (e.g., peer-reviewed journal articles) and instead focus on memorizing the information given to them by their instructors [20]. Many of the students who received the didactic lecture commented on this superficial learning style: 'There was too much factual information given in one sitting with no long-term memory retention'. In contrast, the students who experienced the active learning episode remarked that the format: ' . . enhanced my ability to retain information and created a rational and logical thought process to approach (clinical) cases with'.

\subsection{Use of Group Work or Teamwork}

The group work involved in the active learning episode seemed to be appreciated by the students who commented that their colleagues had often helped them to understand difficult concepts through the discussion within the group: 'Other people's ideas helped me to understand. I benefited from the group's combined effort'. These students remarked that they would not have gained this insight if they had been passive listeners in the traditional lecture as there would have been little opportunity for student-to-student interaction.

Some active learning students commented, however, on the ways in which the quality of their experience was dependent on how they got on as a team. A lack of cohesion within the group was a common reason for not being able to complete the tasks in the allocated time. In a study conducted by Hammond and Kedrowicz [23], first-year veterinary students, working in teams, reported challenges associated with distributing roles and responsibilities and with staying on task, and highlighted the importance of experiential team training to the improvement of team effectiveness. There is, therefore, a need for students to receive formal instruction on how to navigate group work or team processes to allow them to collaborate and apply their knowledge within an authentic environment [23].

\subsection{Communication Skills}

Good communication skills are regarded as essential to function effectively as a veterinary practitioner. The British Veterinary Defence Society, which specializes in the legal defense of veterinarians in negligence claims, has reported that the bulk of its work is generated by poor communication [22]. A meta-analysis conducted by Cake et al. [24] to summarize evidence within the veterinary literature for the importance of professional competencies to career success, highlighted 'communication skills' as the only competency to be well-supported by evidence. The active learning students felt that their learning episode had enhanced their communication skills compared to the didactic-lecture students because completing assigned tasks and solving problems had required effective communication between group members (Figures 1 and 2).

\subsection{Student Confidence and Levels of Participation}

Students in the active learning class remarked on the disruptive effect of students who did not take their classmates' opinions into consideration: 'Equal participation is not always possible when outspoken group members dominate'. Further comments were made about the disadvantages of this teaching approach for students who did not contribute readily to the 
group discussions: 'People get different experiences out of group work and non-assertive group members tend to be disadvantaged'. Indeed, Tarlinton et al. [22] asserted that students who lack the ability to communicate effectively with their peers, either because of language or cultural barriers or a lack of personal confidence, might not be able to participate in group learning methods in a meaningful fashion. In the same study, however, it was reported that students who did not contribute as actively as their classmates in discussions did not learn less than their more vocal peers [22]. A lack of contribution might not, therefore, be a problem for an individual student, but once it adversely affects the group dynamic, the group's learning experience may be inhibited.

It was, however, encouraging to note that many students felt that their confidence had improved during the active learning lesson and found the group activity less intimidating than being asked to answer questions in front of the whole class: 'Working in groups is not as intimidating as shouting out answers in front of the whole class. Group work encourages shy people to participate'; and: 'Although shy, I found it easier to represent my group as a spokesperson and talk to the rest of the class than if I had stood up as an individual to address the class. During the (active learning) session I did not feel as intimidated'.

Nonetheless, it was common for the students facing the active learning activity to initially feel anxious about this new teaching strategy. Since the majority of students' formal pre-professional and professional veterinary education has been associated with classes taught by lecture, the didactic lecture students reported a greater level of comfort with their course expectations: 'It was nice to have the important information emphasised and nice to be told what you are expected to know even though it felt like you were being spoon-fed'; and: 'Didactic lectures ensure that everyone is on the same playing field'.

Some didactic lecture students also felt that their learning experience was better organized and managed than an active learning format may be (Figure 1, Figure 2). Students in the active learning groups experienced ill-defined, real-life problems while students in the didactic lecture group were exposed to more clear-cut, textbook information. Some active learning students expressed frustration when they realized judgments, rather than black-and-white answers, were sometimes necessary when confronted with real problems.

\subsection{Quality of Facilitation}

Many active learning students commented on the ways in which the quality of their experience was dependent on the facilitation style. Grauer et al. [16] found that within a problem-solving learning environment, most students preferred facilitators who provided more guidance rather than those who let them find their own way. If facilitators repeatedly deflected their questions, some students perceived problem-based learning as a waste of their time [15]. Howell et al. [1] found that active learning students wanted consistency in the facilitator's effort and needed more positive reinforcement throughout the course to indicate that they were on the right track.

One didactic lecture student in the present study felt that the traditional lecture was: 'Still effective as long as the lecturer is enthusiastic, interesting, has a strong voice, tells personal anecdotes and holds your attention'. The principal author was given no indication by this student as to whether this had been achieved in the didactic lecture but was left under no illusions by two other students in the didactic lecture group: 'I fell asleep during the lecture'; and: 'The lecture was boring-just listening to someone talk'.

Careful consideration must be given to controlling the noise levels and disruptions caused by rowdy individuals or groups. Collins and Clarke [25] cautioned that although creativity resides within multiple group work, so too does chaos and anarchy. Effective teachers should tolerate enough ambiguity in the classroom to encourage creativity but also strive to keep the class coherent [25].

Students appear more likely to respond positively to a staff facilitator if they like and respect the facilitator and can identify with them [26]. The facilitator, therefore, needs to consider factors that could foster this identification process between student and teacher. Klein [26] suggested that the staff facilitator should initially ask the students about their 
interests and hobbies and should share some personal anecdotes with them. In this instance, acknowledging the rather distasteful subject of diarrhea with light-hearted comments and harmless jokes helped to break down barriers and allowed the students to identify more with the facilitator. In addition, facilitators are more effective if they exhibit enthusiasm and act as passionate advocates for the subject they teach [26]. While this point is noted, it was indeed an awkward challenge for the principal author to act as an enthusiastic and passionate advocate for equine diarrhea.

\subsection{Time Allocation}

The didactic lecture students felt that the time allocated for their learning episode was sufficient in contrast to the active learning students who complained of feeling rushed throughout the session (Figures 1 and 2). Problem-based learning usually involves small groups of students meeting with individual facilitators who help guide them through a problem or case. The active learning approach in the present study involved the use of larger groups with all case-based discussions facilitated by a single facilitator. Concerns about the dissemination of large amounts of material within a relatively short time frame were consistently raised by the active learning students: 'We were rushed for time with insufficient time for discussion available'. Clearly more time needed to be allocated to the active learning class (or fewer tasks assigned) to allow the tasks to be completed in a more leisurely manner.

\subsection{Learning Spaces}

Due to limited flat learning space availability, the principal author was restricted to also using a traditional lecture theater during the active learning activity. This was far from ideal with the groups forced to sit on the back of banks of lecture theater chairs, or even on the floor in the aisles of the lecture theater to enable small group interaction. One of the students complained that: 'The lecture theater layout was a limiting factor'. It is obvious that the active learning activity described in this paper would have been greatly improved if each group could have assembled around circular tables, spread across a flat learning space, with easy access to electricity points and Wi-Fi signal.

Flemming and Storr [27] found that over three quarters of university student respondents indicated that the quality of the learning space affected their learning experience. These students cited the quality of audio-visual equipment, desk space, acoustic quality, seating comfort, natural illumination, and ventilation as important factors in enhancing the quality of learning [27]. The standard classroom (or lecture theater) has been described as having the layout which maintained power relations supportive of didactic transmission approaches to teaching with the pupils passively receiving teacher-controlled information [28].

\section{Pivoting the Active Learning Class to the Online Learning Environment}

Considering the online learning environment favored during the current coronavirus pandemic, the authors are confident that the active learning activity described in this paper would lend itself easily to online delivery. The physical classroom could be simulated using a VoIP such as Zoom or Microsoft's Teams. Indeed, VoIPs can replicate, complement, and even improve upon traditional teaching methods [29]. Notwithstanding the possible technical challenges, such as poor internet connectivity and poor audio or video quality, VoIP technologies allow for real-time interaction involving sound, video, and written text. Such technologies, therefore, can replicate features of face-to-face interactions with students, including the ability to transmit and respond to verbal and nonverbal cues. Furthermore, a platform such as Zoom offers the ability to communicate in real time, via computer, tablet, or mobile device, with students that are geographically dispersed [29].

The group work described in this teaching method could be accommodated using Zoom breakout rooms. The class would initially join the video conference as a whole class and the icebreaker and the first task could then be presented. Students would then move 
into their pre-arranged breakout rooms to tackle each task. The facilitator could move from breakout room to breakout room or communicate with all groups via the Zoom chat function. The students would re-enter the main video conference room after each task to allow one of the group speakers to present their group's findings to the whole of the class. The next task would then be presented, and students would re-enter their breakout room to address the new challenge.

Similar advantages and disadvantages of running an in-person active learning teaching episode would apply to the online version (time constraints, student confidence issues, etc.), although the problem of securing a suitable physical flat learning space would obviously be removed.

\section{Final Thoughts}

In the present study, students seemed to regard the active learning episode as more representative of the way information and problems are encountered in the workplace. These findings aligned with Cooke and Moyle's [30] research on the use of problem-based learning in a nursing curriculum. The nursing students described problem-solving as stimulating, engaging, interesting, fun, and motivating, and referred to the traditional, didactic courses as passive, irrelevant, and boring [30]. In the present study, the active learning veterinary students acknowledged that they were actively involved in the learning process in contrast to their more passive counterparts attending the conventional didactic lecture (Figures 1 and 2).

Students worried, however, that the active learning teaching approach might not prepare them adequately for traditional examinations. It is important, therefore, that the assessment format is appropriately aligned with the active learning approach. Furthermore, students were concerned that the active learning approach provided insufficient content knowledge that might leave them shortchanged on their basic veterinary knowledge. This highlights the need for veterinary education to stop relying on excessive content delivery and to instead focus on teaching students how to access and critically analyze information efficiently and how to solve problems effectively. Students also expressed anxiety at the introduction of a new learning technique, highlighting the need for students to be introduced to the new teaching method gradually and with sensitivity. Students using the active learning approach may also feel uncomfortable participating in group learning activities, especially if their group consists of dominant or disruptive members. Teaching students how to work effectively within a group should be an essential prerequisite to the adoption of an active learning approach. Despite the group activities, active learning demands that students assume more responsibility for their individual learning experience, so teachers must include clear expectations of self-direction and motivation within their subject areas [31].

If delivered face-to-face, the success of the active learning approach relies on the availability of learning spaces amenable to group work (with good access to Wi-Fi and charging stations). In addition, all students need access to suitable computers, laptops, or tablets in order to access the reading material and conduct online research. If the delivery of these active learning episodes is conducted exclusively online, then students' internet access and broadband speeds also become an issue. It is important to recognize that some students may have limited financial resources.

It is also important to acknowledge that the present study represented only a fraction of the fourth-year veterinary curriculum and, therefore, placed relatively little demand on the students' time. Additional research is, therefore, needed to determine the effectiveness of active learning teaching over a time period greater than one hour and in veterinary degree courses at Massey University besides equine medicine. It would be important to determine whether introducing multiple active learning courses would be feasible within the traditional curriculum.

It is also worth noting that many studies promoting the incorporation of active learning into veterinary curricula have been based only on student opinion, gathered through 
questionnaires [2]. The effectiveness of the student-centered teaching and learning method, in the present study, is also based on student satisfaction data and the study would have benefited from a comparison of student performance, between the two student cohorts, using a valid and accurate assessment instrument. Future studies would also benefit from allowing the whole class to receive both teaching methods. In this way, the same group of students would act as the control, allowing them to directly compare the two learning methods.

In addition, there is a risk of participant bias when using student opinion to determine the effectiveness of a new teaching method. Participant bias describes a phenomenon whereby student participants respond in a manner that they think the researcher desires. This bias was, however, hopefully mitigated in the present study by ensuring that all participants were aware of the anonymity and confidentiality of their survey responses.

The present study has demonstrated that the transformation of a single one-hour didactic lecture into an active learning, student-centered activity is a relatively straightforward exercise and is rewarding for both the teacher and the learners. The authors hope that tertiary educators will recognize that the methods and principles of active learning, discussed in this paper, remain applicable and relevant to the online learning environment.

Author Contributions: Conceptualization, S.J.G.G.; methodology, S.J.G.G.; data curation, S.J.G.G., C.F.B., J.L.R. and N.Z.; writing—original draft preparation, S.J.G.G.; writing-review and editing, S.J.G.G., C.F.B., J.L.R. and N.Z. All authors have read and agreed to the published version of the manuscript.

Funding: This research received no external funding.

Institutional Review Board Statement: Not applicable.

Informed Consent Statement: Not applicable.

Data Availability Statement: Not applicable.

Conflicts of Interest: The authors declare no conflict of interest.

\section{References}

1. Howell, N.E.; Lane, I.F.; Brace, J.J.; Shull, R.M. Integration of Problem-Based Learning in a Veterinary Medical Curriculum: First-Year Experiences with Application-Based Learning Exercises at the University of Tennessee College of Veterinary Medicine. J. Vet. Med Educ. 2002, 29, 169-175. [CrossRef]

2. Lane, E.A. Problem-Based Learning in Veterinary Education. J. Vet. Med. Educ. 2008, 35, 631-636. [CrossRef]

3. Birgili, B.; Seggie, F.N.; Oguz, E. The trends and outcomes of flipped learning research between 2012 and 2018 : A descriptive content analysis. J. Comput. Educ. 2021, 8, 365-394. [CrossRef]

4. Herron, M.; Alexander, P.; DiBrito, W. A proposal for problem-solving instruction in veterinary education programs. J. Vet. Med. Educ. (USA) 1990, 17, 21-24.

5. Barr, R.B.; Tagg, J. From teaching to learning-A new paradigm for undergraduate education. Change. J Higher Educ. 1995, 27, $12-26$.

6. Newble, D.; Entwistle, N. Learning styles and approaches: Implications for medical education. Med. Educ. 1986, 20, 162-175. [CrossRef]

7. Ortiz, P.A. Teaching in the time of COVID-19. Biochem. Mol Biol Educ. 2020, 1, 1. [CrossRef] [PubMed]

8. Armitage-Chan, E.; Maddison, J.; May, S.A. What is the veterinary professional identity? Preliminary findings from web-based continuing professional development in veterinary professionalism. Vet. Rec. 2016, 178, 318. [CrossRef] [PubMed]

9. Knowles, M.S. Andragogy, not pedagogy. Adult Leadersh. 1968, 16, 350-352.

10. Merriam, S.B.; Caffarella, R.S.; Baumgartner, L.M. Learning in Adulthood: A comprehensive guide, 3rd ed.; John Wiley and Sons: San Francisco, CA, USA, 2007.

11. Dale, V.H.; Sullivan, M.; May, S.A. Adult learning in veterinary education: Theory to practice. J. Vet. Med. Educ. 2008, 581-588. [CrossRef]

12. Cavalieri, J. Curriculum integration within the context of veterinary education. J. Vet. Med Educ. 2009, 36, 388-396. [CrossRef]

13. Tyler, R.W. Basic Principles of Curriculum and Instruction; University of Chicago press: Chicago, IL, USA, 2013.

14. Prince, M.J.; Felder, R.M. Inductive teaching and learning methods: Definitions, comparisons, and research bases. J. Eng. Educ. 2006, 95, 123-138. [CrossRef]

15. Duhl Glicken, A. Becoming an effective teacher: Applied principles of adult learning. J. Vet. Med Educ. 2004, 31, 268-272. [CrossRef] 
16. Grauer, G.F.; Forrester, S.D.; Shuman, C.; Sanderson, M.W. Comparison of student performance after lecture-based and casebased/problem-based teaching in a large group. J. Vet. Med Educ. 2008, 35, 310-317. [CrossRef]

17. Whitney, M.; Herron, M.; Weeks, B. Preclinical curricular alternatives-history and rationale of problem-based medical-education. J. Vet. Med Educ. 1993, 20, 2-8.

18. Newman, M.J. Problem based learning: An introduction and overview of the key features of the approach. J. Vet. Med Educ 2005, 32, 12-20. [CrossRef] [PubMed]

19. Nandi, P.; Chan, J.; Chan, C.; Chan, P.; Chan, L. Undergraduate medical education: Comparison of problem-based learning and conventional teaching. Hong Kong Med J. 2000, 6, 301-306.

20. Bauer, M.; Bill, R.; Hullinger, R.; Toombs, J.; Teclaw, R. Problem-based learning vs. lecture to teach neurosurgery to third-year veterinary students. J. Vet. Med Educ. (USA) 1992, 19, 22-25.

21. Armstrong, G.R.; Summerlee, A.J.S. In Search of the Citizen Scholar: Modern Pedagogical Approaches Compared. In Universities, the Citizen Scholar and the Future of Higher Education; Arvanitakis, J., Hornsby, D.J., Eds.; Palgrave Macmillan: London, UK, 2016; pp. 21-36.

22. Tarlinton, R.E.; Yon, L.; Klisch, K.; Tötemeyer, S.; Gough, K.C. Confidence as a barrier to the use of problem-based learning in veterinary undergraduate students. J. Vet. Med Educ. 2011, 38, 305-310. [CrossRef] [PubMed]

23. Hammond, S.; Kedrowicz, A.A. Increasing Team Effectiveness Through Experiential Team Training: An Explanatory MixedMethods Study of First-Year Veterinary Students' Team Experiences. J. Vet. Med Educ. 2021, e20210108. [CrossRef]

24. Cake, M.A.; Bell, M.A.; Williams, J.C.; Brown, F.J.L.; Dozier, M.; Rhind, S.M.; Baillie, S. Which professional (non-technical) competencies are most important to the success of graduate veterinarians? A Best Evidence Medical Education (BEME) systematic review: BEME Guide No. 38. Med. Teach. 2016, 38, 550-563. [CrossRef]

25. Collins, S.; Clarke, A. Activity frames and complexity thinking: Honoring both public and personal agendas in an emergent curriculum. Teach. Teach. Educ. 2008, 24, 1003-1014. [CrossRef]

26. Klein, B.G. The 2001 Carl J. Norden Distinguished Teacher Award Teaching the Basic Sciences to Veterinary Students: Science or Art or Both? One Teacher's Journey into Self-Examination. J. Vet. Med Educ. 2001, 28, 82-87. [CrossRef]

27. Fleming, D.; Storr, J. The impact of lecture theatre design on learning experience. Facilities 1999, 17, 231-236. [CrossRef]

28. McGregor, J. Space, power and the classroom. Forum: For promoting 3-19 comprehensive education. Symp. J. 2004, 46, 13-18.

29. Archibald, M.M.; Ambagtsheer, R.C.; Casey, M.G.; Lawless, M. Using zoom videoconferencing for qualitative data collection: Perceptions and experiences of researchers and participants. Int. J. Qual. Methods 2019, 18, 1-8. [CrossRef]

30. Cooke, M.; Moyle, K. Students' evaluation of problem-based learning. Nurse Educ. Today. 2002, 22, 330-339. [CrossRef]

31. Roehl, A.; Reddy, S.L.; Shannon, G.J. The flipped classroom: An opportunity to engage millennial students through active learning strategies. J. Fam. Consum. Sci. 2013, 105, 44-49. [CrossRef] 